\title{
The Canadian Optimal Therapy of COPD Trial: Design, organization and patient recruitment
}

\author{
Shawn D Aaron MD FRCPC ${ }^{1}$, Katherine Vandemheen $\mathrm{BSC}^{1}$, Dean Fergusson PhD ${ }^{1}$, Mark FitzGerald MD FRCPC ${ }^{2}$, \\ Francois Maltais MD FRCPC ${ }^{3}$, Jean Bourbeau MD FRCPC ${ }^{4}$, Roger Goldstein MD FRCPC ${ }^{5}$, \\ Andrew Mclvor MD FRCPC ${ }^{6}$, Meyer Balter MD FRCPC ${ }^{5}$, Denis $\mathrm{O}^{\prime}$ Donnell MD FRCPC
}

SD Aaron, K Vandemheen, D Fergusson, et al. The Canadian Optimal Therapy of COPD Trial: Design, organization and patient recruitment. Can Respir J 2004;11(8):581-585.

BACKGROUND: There are no published studies that have assessed whether adding long-acting beta 2 -agonist bronchodilators and/or inhaled steroids to chronic therapy with tiotropium would provide additional clinical benefit to patients with moderate to severe chronic obstructive pulmonary disease (COPD).

METHODS: The Canadian Optimal Therapy of COPD Trial is a randomized, prospective, double-blind, placebo-controlled, multicentre trial funded by the Canadian Institutes of Health Research that has been designed to determine which combination of inhaled medications will most effectively prevent exacerbations and optimize disease-specific quality of life in patients with COPD. The trial is the first to evolve from the Canadian Thoracic Society Clinical Trials Group. The study will randomize 432 patients with moderate to severe COPD to one of three parallel treatment arms for 52 weeks: tiotropium and fluticasone/salmeterol; tiotropium and salmeterol; or tiotropium and placebo inhaler. The participants will be allowed to use salbutamol as required throughout the trial period.

OUTCOMES: The primary outcome measure is the proportion of patients in the three treatment groups who experienced a respiratory exacerbation within 52 weeks of randomization. Other outcomes that will be assessed over the 52-week trial period will include: changes in disease-specific quality of life and changes in dyspnea, health care use and changes in lung function. A pharmacoeconomic analysis will also be performed to evaluate the cost of these therapies.

RESULTS: The study commenced recruitment in October 2003. It is currently operating at 22 centres across Canada and has randomized 137 patients during the first four months of recruitment. Recruitment is scheduled to continue until April 2005 or until 432 patients have been randomized.

CONCLUSION: The present randomized, placebo-controlled trial offers a unique opportunity to answer the question, what is the best combination of inhaled medications to use for COPD patients? It is hoped that optimal use of inhaled medications will improve patient health and quality of life, reduce patient respiratory exacerbations, and ultimately, reduce health care resource use.

Key Words: Bronchodilators; Chronic obstructive lung disease; Emphysema; Inhaled corticosteroids

\section{L'essai sur le traitement optimal canadien du MPOC : La conception, l'organisation et le recrutement des patients}

HISTORIQUE : Aucune donnée publiée n'a permis d'évaluer si l'ajout
de bronchodilatateurs à béta 2 -agonistes à longue durée d'action ou de
stérö̈des en aérosol à un traitement chronique au tiotropium procurera
des bénéfices cliniques supplémentaires aux patients atteints d'une ma-
ladie pulmonaire obstructive chronique (MPOC) de modérée à grave.
MÉTHODOLOGIE : L'essai sur le traitement optimal canadien du
MPOC est un essai multicentrique prospectif à double insu, aléatoire et
contrôlé contre placebo financé par les Instituts de recherche en santé du
Canada et conçu pour déterminer quelle association de médicaments en
aérosol préviendra avec le plus d'efficacité les exacerbations et optimisera
la qualité de vie reliée à la maladie chez les patients atteints d'une MPOC.
L'essai est le premier à essaimer du groupe d'essais cliniques de la Société
canadienne de thoracologie. Il faudra recruter, de manière aléatoire,
432 patients atteints d'une MPOC modérée à grave dans l'une des trois
ramifications parallèles de traitement de 52 semaines : tiotropium et fluti-
casone-salmétérol, tiotropium et salmétérol ou tiotropium et aérosol
placebo. Les participants seront autorisés à utiliser du salbutamol, au
besoin, tout au long de l'essai. ISSUES : La mesure d'issue primaire correspond à la proportion de patients des trois groupes qui a présenté une exacerbation respiratoire au cours des 52 semaines d'aléation. D'autres issues seront évaluées pendant la période d'essai de 52 semaines, y compris les changements de la qualité de vie propre à la maladie et les modifications à la dyspnée, le recours au système de santé et les changements de fonction pulmonaire. Une analyse pharmacoéconomique sera également exécutée pour évaluer le coût de ces traitements.

RÉSULTATS : Le recrutement pour l'essai a commencé en octobre 2003. Il est entrepris dans 22 centres du Canada, et 137 patients ont été choisis au hasard au cours des quatre premiers mois du recrutement, qui se poursuivra jusqu'en avril 2005 ou jusqu'à ce que 432 patients aient été retenus au hasard.

CONCLUSION : Le présent essai aléatoire et contrôlé contre placebo offre une occasion unique de répondre à la question : "Quel est la meilleure association de médicaments en aérosol pour les patients atteints de MPOC ? » On espère que l'usage optimal de médicaments en aérosol améliorera la santé et la qualité de vie des patients et réduira leurs exacerbations respiratoires ainsi, au bout du compte, que le recours aux ressources de santé.

\footnotetext{
${ }^{1}$ The Ottawa Health Research Institute, University of Ottawa, Ottawa, Ontario; ${ }^{2}$ Department of Medicine, University of British Columbia, Vancouver, British Columbia; ${ }^{3}$ Centre de recherche, Hôpital Laval, Université Laval, Quebec City, Quebec; ${ }^{4}$ Department of Medicine, McGill University, Montreal, Quebec; ${ }^{5}$ Department of Medicine, The University of Toronto, Toronto, Ontario; ${ }^{6}$ Department of Medicine, Dalhousie University, Halifax, Nova Scotia; ${ }^{7}$ The Department of Medicine, Queen's University, Kingston, Ontario

Correspondence: Dr Shawn Aaron, The Ottawa Hospital, General Campus, Room 1812F-501 Smyth Road, Ottawa, Ontario K1H 8L6. Telephone 613-739-6636, fax 613-739-6266, e-mail saaron@ottawahospital.on.ca
} 
$\mathrm{M}$ ost patients with moderate or severe chronic obstructive pulmonary disease (COPD) experience chronic progressive dyspnea that is not alleviated by short-acting beta-agonists. Given this fact, it is not surprising that many patients are treated with multiple inhaled medications in an attempt to optimize their lung function and minimize symptoms (1). According to the Canadian Thoracic Society (CTS) COPD Guidelines (2), the goals of pharmacological therapy should be to control symptoms, improve health status and reduce the frequency of COPD exacerbations.

Over the past several years, numerous studies have been published that have demonstrated that treatment of patients with COPD with inhaled tiotropium (3-5), inhaled salmeterol (6-8) or inhaled steroids/long-acting beta-agonist combination products (9-12) improves dyspnea and quality of life, and decreases exacerbation rates relative to placebo (9). However, there are no studies that have assessed whether therapy with a long-acting beta-agonist plus a long-acting anticholinergic agent would provide greater clinical benefits than therapy with a long-acting anticholinergic agent used alone. Similarly, there are no studies that have assessed whether the addition of an inhaled steroid/long-acting beta-agonist combination product to therapy with a long-acting anticholinergic agent would provide greater benefits than therapy with a long-acting anticholinergic agent used alone.

The additive benefits of combination bronchodilator therapy have been demonstrated in clinical trials that combined the short-acting bronchodilators salbutamol and ipratropium bromide or the long-acting beta-agonist salmeterol with ipratropium bromide (13-15). Because beta-agonists and anticholinergics work through different mechanisms to cause bronchodilation, it makes theoretical and intuitive sense that therapy with both medicines might produce an additional benefit compared with therapy with one alone. However, for many patients, therapy with tiotropium along with inhaled short-acting beta-agonists when necessary, may be all the medication that is required for the control of symptoms. Furthermore, there are safety issues (side effects associated with chronic use of long-acting betaagonists and inhaled steroids) and economic issues (additional costs of these medications) that would argue against routine inhaled medication polypharmacy.

The purpose of the Canadian Optimal Therapy of COPD Trial is to determine what combination of inhaled medications is best to use in patients with moderate to severe COPD. It is hoped that optimal use of inhaled medications will improve patient health and quality of life, reduce patient respiratory exacerbations and, ultimately, save money for the health care system.

\section{TRIAL DESIGN AND METHODS}

The Canadian Optimal Therapy of COPD Trial is a randomized, prospective, double-blind, placebo-controlled, multicentre trial using three parallel treatment arms. The study is recruiting patients over a period of 18 months and follows each recruited patient for a total of 12 months after randomization. The risk of COPD exacerbation increases over the winter months (16) and follow-up for one year ensures that all patients will be followed for at least one high-risk winter season. The total duration of the trial will be 30 months.

\section{Trial intervention}

Patients are being randomly allocated to one of three treatment arms for 52 weeks:
- Tiotropium $18 \mu \mathrm{g}$ once daily + placebo inhaler (two puffs twice a day).

- Tiotropium $18 \mu \mathrm{g}$ once daily + salmeterol $25 \mu \mathrm{g} /$ puff (two puffs twice a day).

- Tiotropium $18 \mu$ g once daily + Advair 250

(GlaxoSmithKline, Canada) (two puffs twice a day; Advair 250 is composed of fluticasone $250 \mu \mathrm{g} /$ puff + salmeterol $25 \mu \mathrm{g} /$ puff in one combination metered-dose inhaler).

Tiotropium is administered through a Handihaler device (Boehringer Ingelheim, Canada). All study patients will be instructed to use inhaled salbutamol when necessary.

The study drug is being administered via a metered-dose inhaler using a spacer device (Aerochamber plus; Trudell Medical, Canada) to ensure adequate lung delivery. The metered dose inhalers containing placebo, salmeterol and salmeterol/fluticasone are identical in taste and appearance, and they are enclosed in identical tamper-proof blinding devices. The medication canisters within the blinding devices are stripped of any identifying labels, so that even if the blinding devices are broken into, the study blind is maintained.

\section{Randomization}

Patients are randomized after informed consent is obtained. The randomization process consists of a computer-generated random listing of the three treatment allocations blocked by variable groups of nine or twelve and stratified by site. Randomization is administered through the central allocation of a randomization schedule and is coordinated by the Ottawa Health Research Institute (Ottawa, Ontario).

\section{Patient selection}

Inclusion criteria were chosen to conform to current American Thoracic Society and Global Initiative for Chronic Obstructive Lung Disease (GOLD) guideline definitions of COPD (17). Those patients with moderate or severe COPD who have had at least one exacerbation of COPD in the last 12 months requiring antibiotics and/or oral steroids are included. Patients must be at least 35 years of age, have a history of at least 10-pack years of smoking, have documented chronic airflow obstruction with a forced expiratory volume in $1 \mathrm{~s}$ :forced vital capacity $\left(\mathrm{FEV}_{1}: \mathrm{FVC}\right)$ ratio of less than 0.70 and a postbronchodilator $\mathrm{FEV}_{1}$ of less than $65 \%$ of predicted.

The exclusion criteria include patients with a history of asthma, a history of chronic congestive heart failure with known severe left ventricular dysfunction, those using chronic oral prednisone, those with known hypersensitivity or intolerance to tiotropium, Advair 250 or salmeterol, and those who have had a recent COPD exacerbation requiring oral or intravenous antibiotics or steroids within the previous 28 days (these patients must wait until they have been off prednisone or antibiotics for 28 days before entering into the study). Also, patients with a history of severe glaucoma or severe urinary tract obstruction, previous lung transplant or lung volume reduction surgery, diffuse bilateral bronchiectasis and those who are pregnant or breastfeeding are being excluded.

\section{Primary outcome measure}

The primary outcome measure is the proportion of patients in the three treatment groups who experienced a respiratory exacerbation 
within 52 weeks of randomization. Respiratory exacerbations is defined as per the 2000 Aspen Lung Conference Consensus definition (18), as "a sustained worsening of the patient's respiratory condition, from the stable state and beyond normal day-to-day variations, necessitating a change in regular medication in a patient with underlying COPD". For operational purposes, an acute change in regular COPD medications is defined as physiciandirected acute use of oral or intravenous steroids, or oral or intravenous antibiotics. The study will monitor patients for exacerbations via monthly telephone calls and via patient visits at four, 20, 36 and 52 weeks after randomization.

It has been suggested that patients who experience frequent exacerbations of COPD (more than two per year) are at higher risk for death, and that these patients experience greater declines in health-related quality of life than those who have fewer exacerbations (19). Furthermore, medical editorials $(20,21)$ that support the use of Advair 250 or salmeterol for COPD do so on the basis that these drugs may decrease COPD exacerbation rates. This end point is also an important economic outcome because patients who have respiratory exacerbations generate higher health care costs for physician visits, hospitalizations and medications (22).

\section{Adjudication of the primary outcome}

A full report, including physician and/or hospital records, describing the circumstances of each suspected exacerbation will be prepared by study personnel. The assembled data from the suspected exacerbation visit will be presented to an Adjudication Committee for review. The Adjudication Committee will be blinded to patient allocation.

\section{Secondary outcomes will include}

- Changes in disease-specific, health-related quality of life for the three treatment groups over the 52-week study period assessed by the St George's Respiratory Questionnaire (23).

- Changes in dyspnea over the 52-week study period assessed by the Baseline and Transitional Dyspnea Indexes (24) and by the dyspnea domain of the Chronic Respiratory Disease Index Questionnaire (25).

- The number of exacerbations that result in urgent visits to a health care provider or emergency department.

- The number of exacerbations that result in hospitalization for COPD.

- Total number of hospitalizations (all cause).

- The time to first exacerbation.

- The mean/median number of exacerbations per patient in each treatment group over the 52-week period.

- Absolute and relative changes in the $\mathrm{FEV}_{1}$ and FVC over the 52-week period.

- Premature discontinuation of study medication, for reason of adverse effects or lack of efficacy, as judged by the patient's physician.

- Patient respiratory symptoms - collected daily using a revised East London Diary Card (19).

\section{Pharmacoeconomic analysis}

A pharmacoeconomic analysis evaluating the costs of these therapies will also be performed. The objectives of the economic analysis will be to estimate the cost of treating a COPD exacerbation for the three proposed treatment strategies; perform a cost minimization analysis by comparing the costs for the three treatment strategies; and conduct a cost-effectiveness analysis. The costeffectiveness analysis will be assessed in terms of the cost per life year gained and quality-adjusted life year gained; and the analysis will be conducted from a health care system perspective. The cost assessment of treatment strategies will include only physician visit, hospitalization and drug costs, because these are assumed to be the major cost drivers for COPD treatment.

\section{Sample size}

For the purposes of the sample size calculation, it was assumed that the proportion of patients who would experience an exacerbation within 52 weeks in the placebo arm would be 55\%. This assumption was based on previous studies $(9,11)$ of patients with moderate to severe COPD that have shown exacerbation rates varying from 1.30 to 1.87 exacerbations/patient/year in the placebo-treated arm.

The Trial Steering Committee determined that a 20\% difference in one-year relapse proportions between the tiotropium and placebo group with either the tiotropium and Advair 250 or tiotropium and salmeterol groups would be the minimal clinically significant difference that would be important for the study to detect. Assuming an 18\% absolute risk reduction between tiotropium and placebo versus tiotropium and salmeterol, an alpha error of 0.025 and a beta error of $0.20,130$ patients per arm or 390 subjects in total are required. To allow for a $5 \%$ noncompliance rate (Lachin formula [26]), a total sample size of 432 subjects or 144 per arm is required. A sample size of 144 per arm provides $89 \%$ power to detect a difference between the second primary comparison (tiotropium and placebo versus tiotropium and Advair 250).

\section{Statistical analysis}

The principal intention-to-treat analysis of the exacerbation proportions in the three treatment groups will be conducted using an unadjusted $\chi^{2}$. If the analysis shows a significant difference among the three treatment groups, two pairwise comparisons will be performed to compare the tiotropium and placebo arm with each of the other two treatment arms. The study is not designed nor powered to compare the difference between tiotropium and salmeterol versus tiotropium and the fluticasone/salmeterol combination product (this comparison would require 9000 patients). Continuous outcome measures, including changes in the quality of life scores, will be analysed using multivariate repeated measures ANOVA. Kaplan-Meier survival curves will be used to describe the probability of remaining exacerbation-free in the two treatment arms. One interim analysis will be performed by the study Data Safety and Monitoring Board once 50\% of patients have been accrued to determine if the experimental therapy is beneficial or hazardous.

\section{Management of the study}

The Trial Coordinating Centre is located at the Ottawa Health Research Institute, Clinical Epidemiology Unit. The Coordinating Centre will monitor recruitment and implement quality assurance policies, as well as develop and maintain the study database. 
TABLE 1

Participating study sites as of February 2004

\begin{tabular}{|c|c|}
\hline Physician & City \\
\hline Shawn Aaron & Ottawa, Ontario \\
\hline John Anthony & Scarborough, Ontario \\
\hline Meyer Balter & Toronto, Ontario \\
\hline Greg Berg & Sault Sainte Marie, Ontario \\
\hline Jean Bourbeau & Montreal, Quebec \\
\hline Robert Cowie & Calgary, Alberta \\
\hline Gerald Cox & Hamilton, Ontario \\
\hline Mark FitzGerald, Jeremy Road & Vancouver, British Columbia \\
\hline Gordon Ford & Calgary, Alberta \\
\hline George Fox & St John's, Newfoundland \\
\hline Roger Goldstein & Toronto, Ontario \\
\hline Richard Hodder & Ottawa, Ontario \\
\hline Victor Hoffstein & Toronto, Ontario \\
\hline Francois Maltais & Quebec City, Quebec \\
\hline Darcy Marciniuk & Saskatoon, Saskatchewan \\
\hline Irvin Mayers & Edmonton, Alberta \\
\hline David McCormack & London, Ontario \\
\hline Andrew Mclvor & Halifax, Nova Scotia \\
\hline Denis O’Donnell & Kingston, Ontario \\
\hline Elizabeth Powell & Brampton, Ontario \\
\hline Sat Sharma & Winnipeg, Manitoba \\
\hline Noe Zamel, Kenneth Chapman & Toronto, Ontario \\
\hline
\end{tabular}

The Trial Steering Committee consists of the Chair, the trial statistician/methodologist and the other six respirologist members of the Steering Committee. The Steering Committee is overseeing all aspects of the trial. Specifically, the Committee will develop or modify all policies regarding the daily operations of the trial; be responsible for the writing of all publications; may also develop modifications to the design, execution and analysis of the trial; and have ultimate responsibility for data management and quality assurance.

\section{Recruitment to date}

The study commenced recruitment in October 2003 at 10 centres across Canada. As of February 2004, 22 centres were participating (Table 1). The study involves investigators situated at every medical school in Canada, with the exception of Sherbrooke, Quebec. One hundred thirty-seven patients were randomized over the first four months of the study from October 2003 to February 2004. Figure 1 shows projected and actual recruitment rates for the study from October 2003 to February 2004. Although recruitment is on schedule, at least five more sites are planned to be added to meet scheduled recruitment timelines. Recruitment is scheduled to continue until April 2005 or until 432 patients have been randomized. The study will terminate once the last recruited patient has completed 12 months of follow-up.

\section{DISCUSSION}

The present study represents the first trial to evolve from the CTS Clinical Trials Group. The CTS Clinical Trials Group is

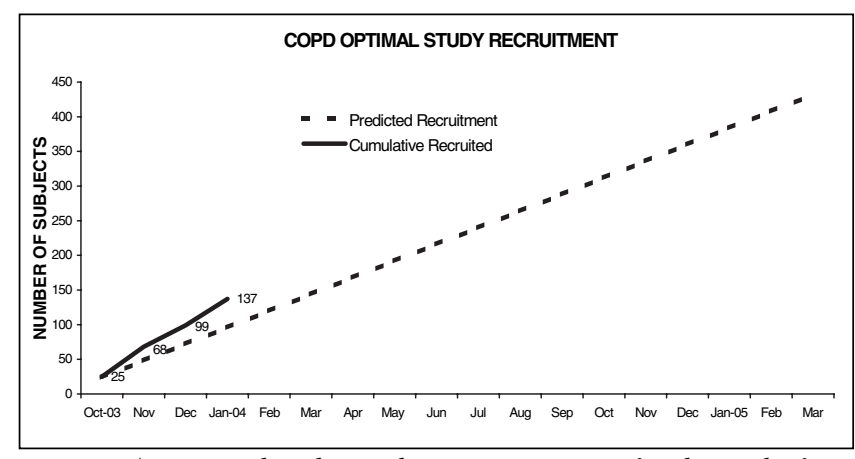

Figure 1) Projected and actual recruitment rates for the study from October 2003 to February 2004. COPD Chronic obstructive pulmonary disease

made up of representatives from each of the major medical schools in Canada; its goal is to produce high-quality respiratory clinical trials.

There have been major challenges involved in launching The Canadian Optimal Therapy of COPD Trial. The first and toughest challenge has been to secure a placebo product. Initially, we tried to have a placebo inhaler manufactured for the study, but discovered that the one company that manufactured placebo inhalers for commercial production had ceased producing their placebo product after the passage of The Kyoto Protocol. We next tried to enlist the help of the pharmaceutical company that manufactures Advair 250 and Serevent (GlaxoSmithKline, Canada). Although we tried to convince the company of the merits of providing us with a placebo that would match their Advair 250 and Serevent products, the company ultimately refused to supply our study with placebo inhalers. Thankfully, another pharmaceutical company agreed to supply us with placebo inhalers and blinding devices for our study without restrictions.

A second challenge has involved competition for patients. There are several other ongoing clinical trials in Canada currently recruiting COPD patients. Most of these other COPD trials are industry-sponsored, and these trials traditionally reimburse individual study sites at higher rates than Canadian Institutes of Health Research-sponsored trials. Thus, we have found that we are faced with competition for patients, and are at a distinct disadvantage because remuneration for our study is less than industry-sponsored studies. Thankfully, the study investigators involved in the present trial are committed to answering the study question and remain committed to the idea of pursuing respiratory clinical trials independent of industry.

The Canadian Optimal Therapy of COPD study is designed to answer the question: "What is the best combination of inhaled medications to use for COPD patients?" As a corollary, the study will also help validate proposed treatment algorithms contained in the CTS COPD Guidelines (2). Ultimately, the results of the trial will be applied to ensure that optimal treatment will be given at the lowest cost and lowest risk of potential drug toxicity. It is hoped that the optimal use of inhaled medications will improve patient health and quality of life, reduce patient respiratory exacerbations and, ultimately, reduce the use of health care resources. 


\section{REFERENCES}

1. Jackevicius CA, Chapman KR. Prevalence of inhaled corticosteroid use among patients with chronic obstructive pulmonary disease: A survey. Ann Pharmacother 1997;31:160-4.

2. O'Donnell DE, Aaron SD, Bourbeau J, et al. Canadian Thoracic Society recommendations for management of chronic obstructive pulmonary disease - 2003. Can Respir J 2003;10(Suppl A):11A-65A.

3. Casaburi R, Mahler DA, Jones P, et al. A long-term evaluation of once-daily inhaled tiotropium in chronic obstructive pulmonary disease. Eur Respir J 2002;19:217-24.

4. Vincken W, van Noord JA, Greefhorst AP, et al. Improved health outcomes in patients with COPD during 1 yr's treatment with tiotropium. Eur Respir J 2002;19:209-16.

5. Donohue JF, van Noord JA, Bateman ED, et al. A 6-month, placebo-controlled study comparing lung function and health status changes in COPD patients treated with tiotropium or salmeterol. Chest 2002;122:47-55.

6. Jones PW, Bosh TK. Quality of life changes in COPD patients treated with salmeterol. Am J Respir Crit Care Med 1997;155:1283-9.

7. Mahler DA, Donohue JF, Barbee RA, et al. Efficacy of salmeterol xinafoate in the treatment of COPD. Chest 1999; 115:957-65.

8. Rennard SI, Anderson W, ZuWallack R, et al. Use of a long-acting inhaled beta2-adrenergic agonist, salmeterol xinafoate, in patients with chronic obstructive pulmonary disease. Am J Respir Crit Care Med 2001;163:1087-92.

9. Calverley P, Pauwels R, Vestbo J, et al; TRial of Inhaled STeroids ANd long-acting beta2 agonists study group. Combined salmeterol and fluticasone in the treatment of chronic obstructive pulmonary disease: A randomised controlled trial. Lancet 2003;361:449-56. Erratum in: 2003;361:1660.

10. Mahler DA, Wire P, Horstman D, et al. Effectiveness of fluticasone propionate and salmeterol combination delivered via the Diskus device in the treatment of chronic obstructive pulmonary disease. Am J Resp Crit Care Med 2002;166:1084-91.

11. Szafranski W, Cukier A, Ramirez A, et al. Efficacy and safety of budesonide/formoterol in the management of chronic obstructive pulmonary disease. Eur Respir J 2003;21:74-81. Erratum in: 2003;21:912

12. Hanania NA, Darken P, Horstman D, et al. The efficacy and safety of fluticasone propionate $(250 \mu \mathrm{g}) /$ salmeterol $(50 \mu \mathrm{g})$ combined in the diskus inhaler for the treatment of COPD. Chest 2003;124:834-43.

13. Campbell S. For COPD a combination of ipratropium bromide and albuterol sulfate is more effective than albuterol base. Arch Intern Med 1999;159:156-60.
14. Chapman KR, Arvidsson P, Chuchalin AG, et al; International study group. The addition of salmeterol $50 \mu \mathrm{g}$ bid to anticholinergic treatment in patients with COPD: A randomized, placebo controlled trial. Can Respir J 2002;9:178-85.

15. van Noord JA, de Munck DR, Bantje TA, Hop WC, Akveld ML, Bommer AM. Long-term treatment of chronic obstructive pulmonary disease with salmeterol and the additive effect of ipratropium. Eur Respir J 2000;15:878-85.

16. Canadian Institute for Health Information, Canadian Lung Association, Health Canada, and Statistics Canada. Respiratory Disease in Canada. Ottawa: Health Canada; 2001.

17. Pauwels RA, Buist AS, Calverley PM, Jenkins CR, Hurd SS; GOLD Scientific Committee. Global strategy for the diagnosis, management, and prevention of chronic obstructive pulmonary disease. NHLBI/WHO Global Initiative for Chronic Obstructive Lung Disease (GOLD) Workshop summary. Am J Crit Care Med 2001;163:1256-76.

18. Rodriguez-Roisin R. Toward a consensus definition for COPD exacerbations. Chest 2000;117( 5 Suppl 2):398S-401S.

19. Seemungal TA, Donaldson GC, Paul EA, Bestall JC, Jeffries DJ, Wedzicha JA. Effect of exacerbation on quality of life in patients with chronic obstructive pulmonary disease. Am J Respir Crit Care Med 1998;157:1418-22.

20. Pauwels R. Inhaled glucocortisteroids and chronic obstructive pulmonary disease. How full is the glass? Am J Resp Crit Care Med 2002;165:1579-80.

21. Anthonisen NR. Inhaled steroids in chronic obstructive pulmonary disease. Can Respir J 2002;9:11-2.

22. Miravitlles M, Murio C, Guerrero T, Gisbert R; DAFNE (Decisiones sobre Antibioticoterapia y Farmacoeconomía en la EPOC) Study Group. Pharmacoeconomic evaluation of acute exacerbations of chronic bronchitis and COPD. Chest 2002;121:1449-55

23. Jones PW, Quirk FH, Baveystock CM, Littlejohns P. A selfcomplete measure of health status for chronic airflow limitation. The St George's Respiratory Questionnaire. Am Rev Respir Dis 1992;145:1321-7.

24. Mahler DA, Weinberg DH, Wells CK, Feinstein AR. The measurement of dyspnea. Contents, interobserver agreement, and physiologic correlates of two new clinical indexes. Chest 1984;85:751-8.

25. Guyatt GH, Berman LB, Townsend M, Pugsley SO, Chambers LW. A measure of quality of life for clinical trials in chronic lung disease. Thorax 1987;42:773-8.

26. Lachin JM, Foulkes MA. Evaluation of sample size and power for analyses of survival with allowance for nonuniform patient entry, losses to follow-up, noncompliance, and stratification. Biometrics 1986;42:507-19. 


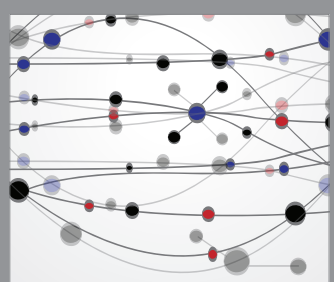

The Scientific World Journal
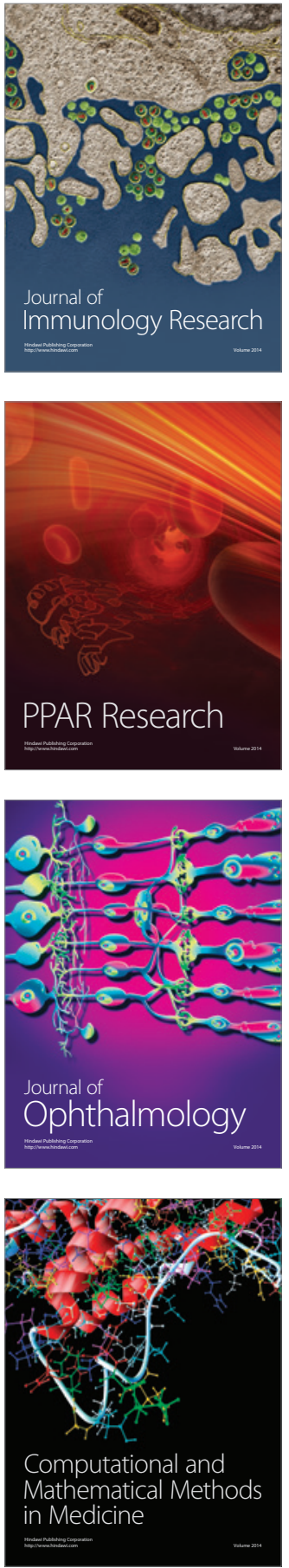



Gastroenterology Research and Practice



\section{Hindawi}

Submit your manuscripts at

http://www.hindawi.com

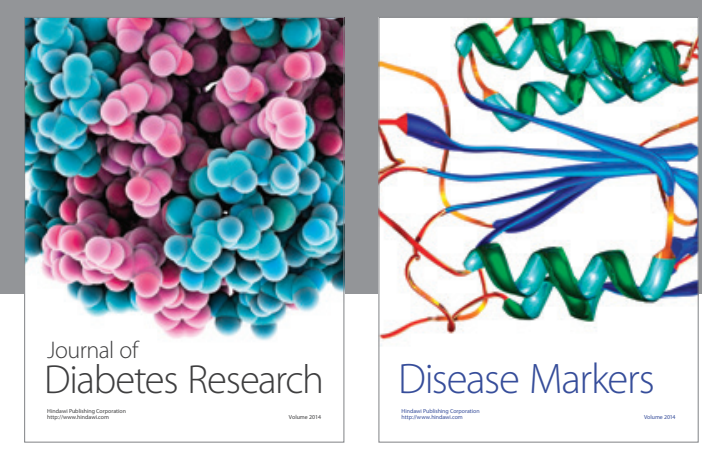

Disease Markers
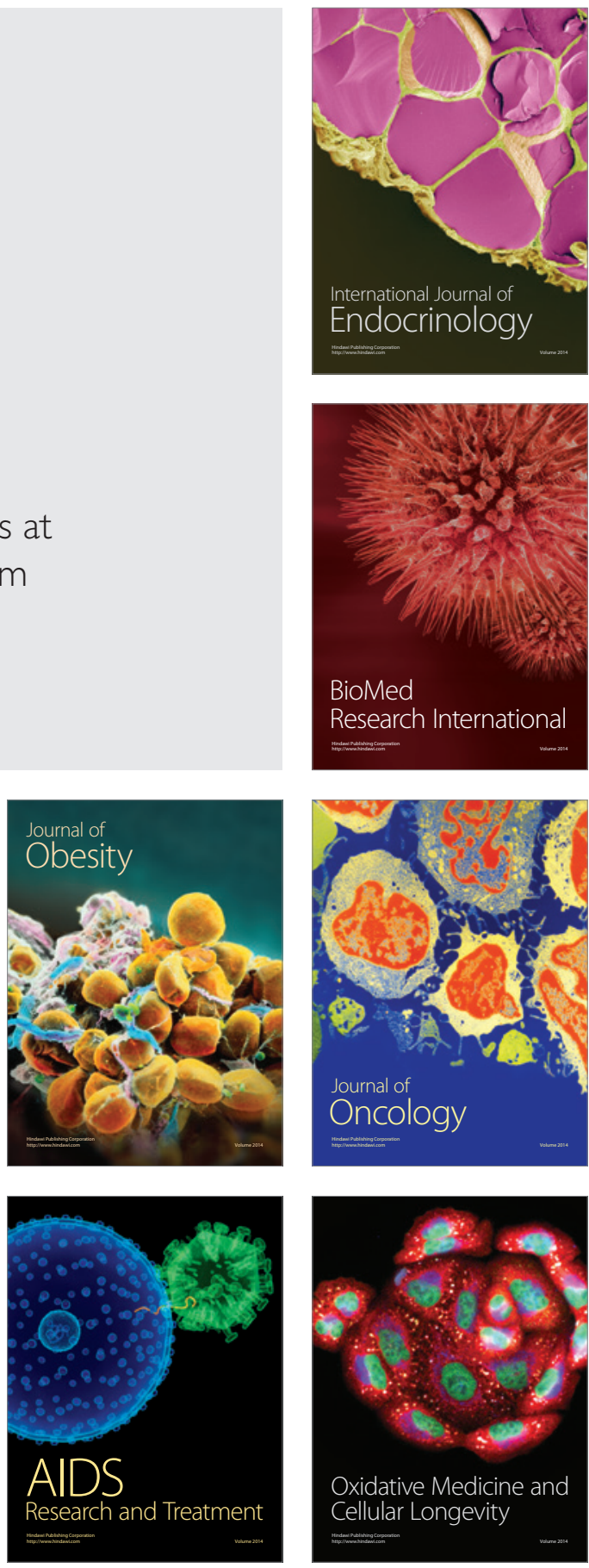